Continuous Microflow PhotoRAFT Polymerization

Peer-reviewed author version

WENN, Benjamin \& JUNKERS, Tanja (2016) Continuous Microflow PhotoRAFT

Polymerization. In: MACROMOLECULES, 49(18), p. 6888-6895.

DOI: 10.1021/acs.macromol.6b01534

Handle: http://hdl.handle.net/1942/22692 


\title{
Continuous Microflow PhotoRAFT
}

\section{Polymerization}

\author{
Benjamin Wenn ${ }^{a}$, Thomas Junkers ${ }^{a, b^{*}}$
}

${ }^{\text {a }}$ Polymer Reaction Design Group, Institute for Materials Research (IMO), Universiteit Hasselt, Martelarenlaan 42, B-3500 Hasselt, Belgium.

${ }^{\mathrm{b}}$ IMEC associated lab IMOMEC, Wetenschapspark 1, B-3590 Diepenbeek, Belgium. KEYWORDS photopolymerization, RAFT, flow reactors, acrylates, UV-initiation, Iniferter

\section{ABSTRACT}

PhotoRAFT (reversible addition fragmentation radical transfer) polymerizations are investigated for reactions induced by conventional radical photoinitiators. As demonstrated, this rather simple photoRAFT reaction show similar outcomes compared to other recently introduced photopolymerizations, such as photoelectron transfer RAFT or copper-mediated photopolymerization. Despite the general notion that classically initiated photoRAFT yields unsatisfactory results, it is shown that good results can be achieved when conditions are selected accordingly. Not only the type of initiator is of importance, also light intensity, RAFT agent to initiator concentration and reaction temperature is of importance. For the initiator benzoin, optimal polymerizations are obtained when the initiator is used in a ratio of 0.25 to the initial RAFT agent at $60{ }^{\circ} \mathrm{C}$ reaction temperature and $30 \mathrm{~mW} \mathrm{~cm}^{-2}$ light intensity $(360 \mathrm{~nm})$. Chain 
lengths of the polymer can be tuned efficiently and block copolymers are accessible from the process despite some slight loss in chain-end fidelity during polymerizations. Additionally, the choice of initiator is shown to have a large effect on the polymerization, which can be routed to different decomposition rate coefficient under the same illumination conditions. Decomposition rates of the photoinitiators are under flow conditions very high and polymerizations proceed to completion after all initiator is used up via a photoiniferter mechanism.

\section{Introduction}

In recent years, a remarkable renaissance of photoreactions for solution-based synthetic chemistry is observed ${ }^{1}$ that is connected with a strong movement towards continuous flow processing, with much interest coming not only from the academic field, but also from industry. $^{2}$ To date only few photoreactions are employed in synthesis on significant scale, most of them being located in the realm of pharmaceutical chemistry where photocycloadditions can give access to specific structures that are inaccessible from thermally activated reactions. ${ }^{3}$ Classical batch photochemistry is often tedious and expensive, and frequently suffers from severe limitations in selectivity and achievable yield. Photoflow reactors on the other hand feature several advantages over conventional batch chemistry approaches, which are directly correlated to the inherently small optical pathlengths that need to be passed in such reactors. Batch reactors on the other hand are associated with significant intensity gradients. These gradients result in a loss of reaction efficiency, require high initial light intensities that trigger side reactions and only a few options exist to overcome this limitation. ${ }^{4}$ In consequence, various commercially available as well as homemade continuous flow reactor setups that are easy to build and operate have been proposed as viable workarounds to make photochemistry more attractive for synthesis. ${ }^{5}$ Most reactor systems described consist of a thin $(<2 \mathrm{~mm}$ outer 
diameter) fluoropolymer tubing wrapped tightly around a UV-light source. The thin tubing keeps optical pathlengths at any point short, in this way giving access to efficient light penetration without occurrence of significant gradients even for somewhat larger reactor volumes (note that flow reactors often do not require large volumes in order to afford larger amounts of products, and upscaling is often comparatively simple when compared to batch reactors).

The field of photopolymerizations featured until recently the same limitation as small molecule photoreactions. Photopolymerizations are often only used broadly in coating and film design, and for network formation for example in dental restoratives. Only little efforts were made to exploit such reactions in synthesis of materials from solution, despite a broad variety of photoinitiators and processes being available, especially in the realm of free radical polymerization. This lack of interest stemmed mostly from a certain incompatibility of photochemistry with advanced polymer synthesis techniques, and the general difficulty to upscale photoreactions in an economic way. Still, in the last few years, photoinduced reaction modes for most controlled radical polymerization techniques have been identified and are now developing rapidly, allowing to access the full range of complex macromolecular synthesis targets via such methods.

Hence unsurprisingly, also in the area of polymer chemistry the advantages of photoflow reactors have been picked up in order to perform continuous photoinitiated polymerizations. ${ }^{1,}$ 4, 6 The main focus in most literature reports is thereby put on reversible deactivation radical polymerization (RDRP) techniques, with photo-induced metal-mediated polymerizations being the most popular choice. Junkers and coworkers reported on the synthesis of acrylate and methacrylate homo- and block copolymers via copper-mediated polymerizations. ${ }^{7}$ Melker et al. used an iridium complex instead and looked in detail at the influence of different tubing materials on the polymerization. ${ }^{8}$ Photoinduced polymerization of vinyl acetate with a cobalt 
complex was reported by Detrembleur and coworkers. ${ }^{9}$ Recently, the first successful photoinitiated reversible addition-fragmentation radical transfer (RAFT) polymerization in a continuous flow reactor using a trithiocarbonate compound as a transfer agent was reported, for polymers with molecular weights of up to $100000 \mathrm{~g} / \mathrm{mol}$ and concomitantly low dispersity. ${ }^{10}$ Gardiner et al. recently reported the first RAFT polymerization using conventional photoinitiators in a continuous flow reactor. ${ }^{5 \mathrm{~b}}$ Classically initiated RAFT polymerizations are sometimes seen as less efficient when compared to recent developments such as photoelectron transfer RAFT (PET-RAFT), which was demonstrated to be a highly efficient technique for a variety of complex synthesis targets. ${ }^{11}$ PET-RAFT makes use of specific catalysts that absorb light followed by photoelectron transfer to create propagating radicals from the RAFT agent. The study by Gardiner and coauthors on first glance seems to confirm that notion as materials with rather large dispersity were obtained in their flow study and hence materials with low structural fidelity. Yet, reactions were optimized for maximum conversion per time, and not necessarily for maximum precision in chain structure and dispersity, giving room to speculation if the reactions could not be further optimized. The question if RAFT polymerization may perform to the same standards as other conventionally initiated state-of-the art RDRP methods is thus still open. Techniques such as PET-RAFT certainly display some fundamental advantages like the ability to choose the wavelength of the incident light, however, they may not be as unique when it comes to the level of polymerization control that may be achievable.

RAFT differs from most other photoRDRP methods due to its degenerative transfer mechanism that requires a constant supply of radicals into the system during the full time span of polymerization. As already indicated above, in principle conventional initiation sources may be used, such as classical radical photoinitiators. However, Qiao and coworkers demonstrated ${ }^{12}$ that RAFT agents and RAFT-polymers may elegantly act as radical initiators themselves under UV- and visible light irradiation, following a photoiniferter mechanism. ${ }^{13}$ The RAFT 
mechanism and its additional iniferter-like radical initiation are summarized in Scheme $1 .^{14}$ Interestingly, the iniferter initiation pathway creates polymer species which are identical to typical RAFT products, and hence a discrimination between reaction pathways is difficult to achieve and iniferter polymerization may only differ in reaction rate from classically initiated RAFT. Yet, photoiniferter initiation is advantageous, as the classical features such as structural integrity and ability to chain extend are preserved in this pathway. Further, also no endgroup exchange occurs in photoiniferter compared to use of exogenous radical sources, thus in principle even increasing the endgroup fidelity of products. In fact, Qiao and coworkers had demonstrated that photoRAFT polymerizations may be reactivated several times in complete absence of any exogenous radical source with very high success.

In here, we explore the use of conventional photoinitiators deeper for continuous flow photoRAFT polymerization with respect not only to polymerization rate, but also level of control that is achievable in these reactions. Pure iniferter polymerizations are comparatively slow, and hence in principle disadvantageous, even if they are in principle able to deliver products with higher purity. ${ }^{15}$ If successful, then classically initiated photoRAFT may still be advantageous over the more recent developments in the field, and at least for labscale polymerization remain the method of choice for synthetic polymer chemists. Different initiators are screened to test for the influence of the choice of initiator with respect to reaction rate, and product purity. Additionally, polymerizations are compared to the iniferter initiation mechanism in order to elucidate the contribution of the iniferter mechanism to the overall polymerization. As mentioned, in contrast to the study by Gardiner et al., focus is thereby not only put on time/yield correlations, but also on product dispersities, as this is often seen as a quality mark of RAFT polymers and is required to allow for block copolymer synthesis. In the following, also the influence of initiator concentration, light intensity and the reaction temperature (an often overlooked factor in photoreactions) is described. Then, block copolymer 
synthesis is investigated to elucidate if carefully optimized photoRAFT polymerizations can reach a similar control as for example copper-mediated radical photopolymerizations.

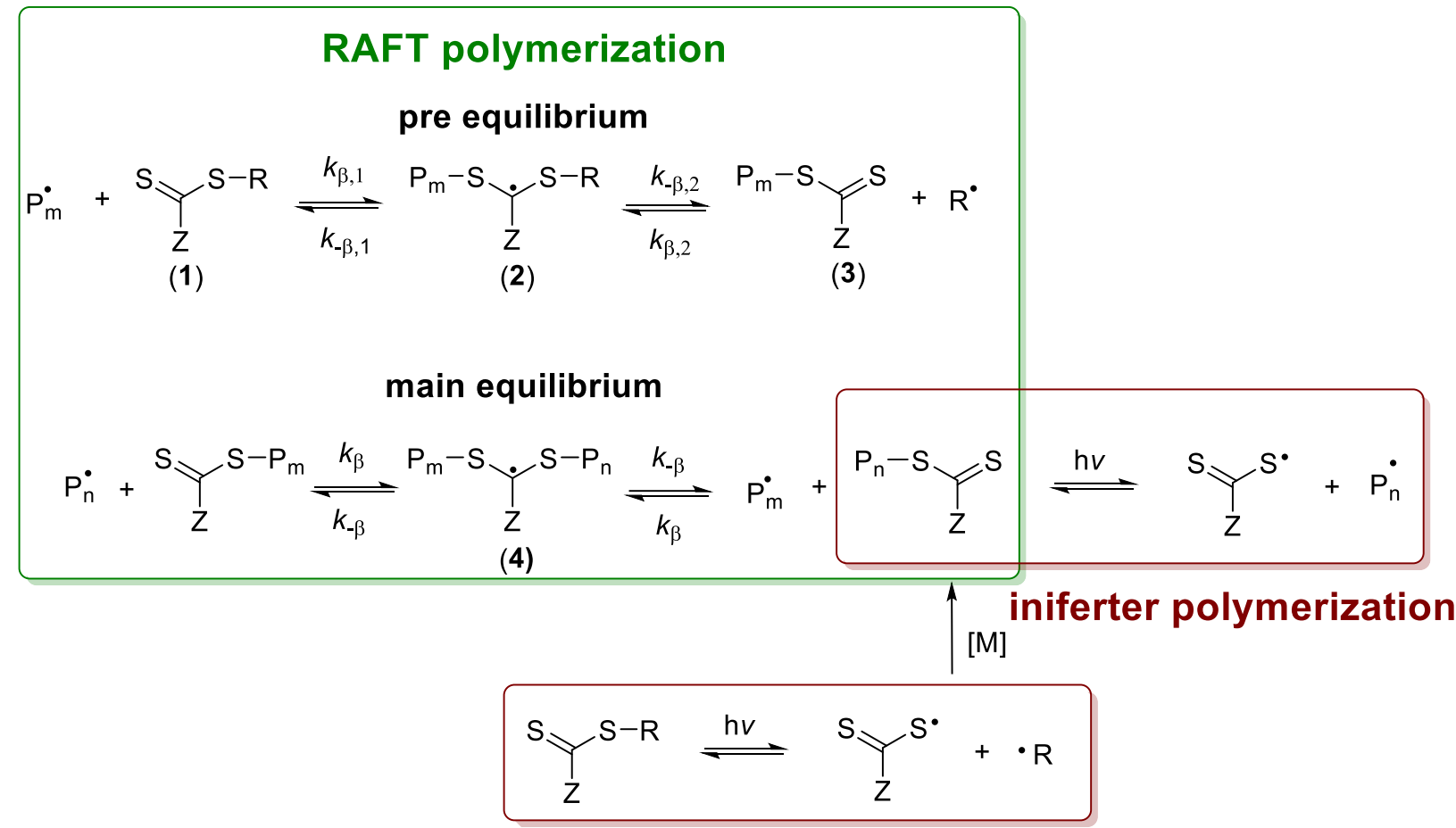

Scheme 1 Mechanism of RAFT polymerization as well as the iniferter mechanism.

\section{Materials and Methods}

The monomers $n$-butyl acrylate ( $n$ BA, Acros , 99\%) and metyl acrylate (MA, Acros, 99\%) were purified over a basic alumina column prior to use. $n$-Butyl acetate (Acros, 99\%), benzoin (Janssen Chimica, 98\%), 2,2-dimethoxy-2-phenylacetophenone (DMPA, Acros, 99\%), phenylbis(2,4,6-trimethylbenzoyl)phosphine oxide (IRGACURE 819, Tokyo Chemical Industry, 96\%) and 2-hydroxy-4'-(2-hydroxyethoxy)-2-methylpropiophenone (IRGACURE 2959, Sigma Aldrich, 98\%) were used as received. 2([(Dodecylsulfanyl)carbonothioyl]sulfanyl) propanoic acid (DoPAT) was synthesized as reported in literature. ${ }^{16}$ 
${ }^{1} \mathrm{H}$ NMR spectra were measured with 64 scans and 12 seconds delay in deuterated chloroform on a $400 \mathrm{MHz}$ Oxford Instruments Ltd. NMR spectrometer.

For size exclusion chromatography (SEC) measurements a Tosoh EcoSEC HLC-8230GPC, equipped with an autosampler and a Tosoh EcoSEC RI differential refractive index detector was used. The device was equipped with a PSS guard SVD $(50 \times 7.5 \mathrm{~mm})$ and three PSS SDV analytical linear XL $(5 \mu \mathrm{m}, 300 \times 7.5 \mathrm{~mm})$ columns. They were kept at $40{ }^{\circ} \mathrm{C}$ and had a molecular weight range between $1 \times 10^{2}$ and $1 \times 10^{6} \mathrm{~g} \cdot \mathrm{mol}^{-1}$. THF with toluene as flow marker was used as eluent with a flow rate of $1 \mathrm{~mL} \cdot \mathrm{min}^{-1}$. For calibration PSS Laboratories linear narrow polystyrene standards with a range of $470-7.5 \times 10^{6} \mathrm{~g} \cdot \mathrm{mol}^{-1}$ were used. MHKS parameters $\left(\alpha=0.70, \mathrm{~K}=14.1 \times 10^{-5} \mathrm{dL} \cdot \mathrm{g}^{-1} \text {, THF } 30{ }^{\circ} \mathrm{C}\right)^{17}$ were applied for analysis.

As microflow reactor a Labtrix Start R2.2 (Chemtrix BV) system was used. The system was equipped with a glass microcreactor (3227) with an internal volume of $19.5 \mu \mathrm{L}$ (width channel $=300 \mu \mathrm{m}$, depth channel $=120 \mu \mathrm{m})$. A Fusion 100 classic syringe pump (Chemyx Inc.) with two gas-tight $1 \mathrm{~mL}$ SGE syringes (Trajan Scientific Australia Pty Ltd.) was used for reaction solution delivery. Through the control of the delivery rate of the syringes the residence time (reaction time) can be changed. As a UV light source an OmniCure S1000 system with a 100 W high pressure mercury vapor short arc lamp (spectral emission: $320-500 \mathrm{~nm}$, peak at 365 $\mathrm{nm}$ ) was used. The identical setup was used in previous studies. ${ }^{7 b, 9}$

Light intensity was measured with a RM-12 (Opsytec Dr. Groebel GmbH) UV-Vis radiometer. The radiometer was equipped with an UV-A $(315-400 \mathrm{~nm})$ sensor which was calibrated with an Osram L100w/79 lamp. 


\section{Experimental Procedures}

\section{General polymerization procedure}

For all polymerizations the monomer $n \mathrm{BA}$ was added into an amber glass vial. In another amber glass vial the photo initiator, the RAFT agent (DoPAT) and the solvent (BuAc) were mixed. The vials were degassed using nitrogen purging for 4 minutes. Afterwards, two gas-tight glass syringes were filled with the reagents and injected into the microflow reactor using a syringe pump. Different reaction times (residence times) were screened by changing the syringe pump flow rates. Reaction times of 2, 4, 6, 8, 12,16 and 20 minutes were screened, by adjusting flow rates to 5.0 (2 $\mathrm{min}), 2.5(4 \mathrm{~min}), 1.67(6 \mathrm{~min}), 1.25(8 \mathrm{~min}), 0.83(12 \mathrm{~min}), 0.625(16 \mathrm{~min}), 0.50$ $\mu \min ^{-1}(20 \mathrm{~min})$ per syringe.

\section{Synthesis of pnBA at different temperatures}

The general polymerization procedure was applied by using the following amounts: $7.02 \mathrm{mmol}$ (0.90 g, 20 equiv) $n \mathrm{BA}, 0.0878 \mathrm{mmol}(0.02 \mathrm{~g}, 0.25$ equiv) Benzoin, $0.35 \mathrm{mmol}(0.12 \mathrm{~g}, 1$ equiv) DoPAT and $1.0 \mathrm{~mL}$ of BuAc. Different temperatures were screened with a residence time of 12 minutes and a light intensity of $30 \mathrm{~mW} \mathrm{~cm}^{-2}$.

\section{Influence of light intensity}

The reaction was performed at $60{ }^{\circ} \mathrm{C}$ with varying light intensities. Following the general polymerization procedure with these values: $7.02 \mathrm{mmol}(0.90 \mathrm{~g}, 20$ equiv) $n \mathrm{BA}, 0.0878 \mathrm{mmol}$ (0.02 g, 0.25 equiv) Benzoin, $0.35 \mathrm{mmol}$ (0.12 g, 1 equiv) DoPAT and $1.0 \mathrm{~mL}$ of BuAc. Light intensities of $5,10,20,30,50$ and $70 \mathrm{~mW} \mathrm{~cm}^{-2}$ were used. The intensities were varied by 
changing the iris-opening of the employed Omnicure UV-lamp. All intensities were measured with the radiometer described above.

\section{Reactions for different photo-initators}

$7.02 \mathrm{mmol}$ ( $0.90 \mathrm{~g}, 20$ equiv) $n \mathrm{BA}, 0.25$ equiv photo initiator, $0.35 \mathrm{mmol}(0.12 \mathrm{~g}, 1$ equiv) DoPAT and 1.0 mL BuAc were prepared following the general polymerization procedure and using different photo initiators (benzoin, DMPA, Irgacure 819 and Irgacure 2959). One reaction was carried out without adding a photo initiator. All reactions were done at $60{ }^{\circ} \mathrm{C}$ with a light intensity of $30 \mathrm{~mW} \mathrm{~cm}^{-2}$.

\section{Synthesis of pnBA- $b$-pMA block copolymers}

Poly(n-butyl acrylate) (0.0784 mmol, $0.2312 \mathrm{~g}, 1$ equiv, $\left.Ð=1.18, M_{n}=2900 \mathrm{~g} \mathrm{~mol}^{-1}\right)$ was synthesized following the general polymerization procedure and used as a macroinitiator. It was mixed in an amber glass vial with $0.0196 \mathrm{mmol}(0.0042 \mathrm{~g}, 0.25$ equiv) benzoin and $0.4 \mathrm{~mL}$ BuAc. In another amber glass vial $1.5681 \mathrm{mmol}(0.1350 \mathrm{~g}, 20$ equiv) MA and $0.25 \mathrm{~mL} \mathrm{BuAc}$ were mixed. Both vials were purged with nitrogen for 4 minutes. Reaction conditions of $60{ }^{\circ} \mathrm{C}$ and $30 \mathrm{~mW} \mathrm{~cm}^{-2}$ were set to perform the chain extension. 


\section{Results and Discussion}

The use of flow reactors for photoRDRP reactions is an emerging field in academic research and industry. ${ }^{4}$ Fast reaction rates are thereby important for the economic use of flow reactors. A trithiocarbonate was thus chosen as control agent for the tests described herein, as best results have been reported before in flow for these specific RAFT agents, and because in an ideal case they than the supporting iniferter initiation mechanism shown above. ${ }^{13 c,}$ 13e, 18 All polymerizations were carried out in $n$-butyl acetate (BuAc) as solvent, 2-(dodecylthiocarbonothioylthio)propionic acid (DoPAT) as RAFT-Agent and $n$-butyl acrylate $(n \mathrm{BA})$ as monomer. To screen the reactions conveniently in a broad range of conditions, a Labtrix Start setup (Chemitrx) with a glass chip microreactor (Reactor volume: $19.5 \mu \mathrm{L}$ ) was employed in all experiments (see Figure 1). As light source, an OmniCure S1000 system with a mercury medium pressure lamp $\left(\lambda_{\max }=365 \mathrm{~nm}\right.$, max. $\left.100 \mathrm{~W}\right)$ was employed.

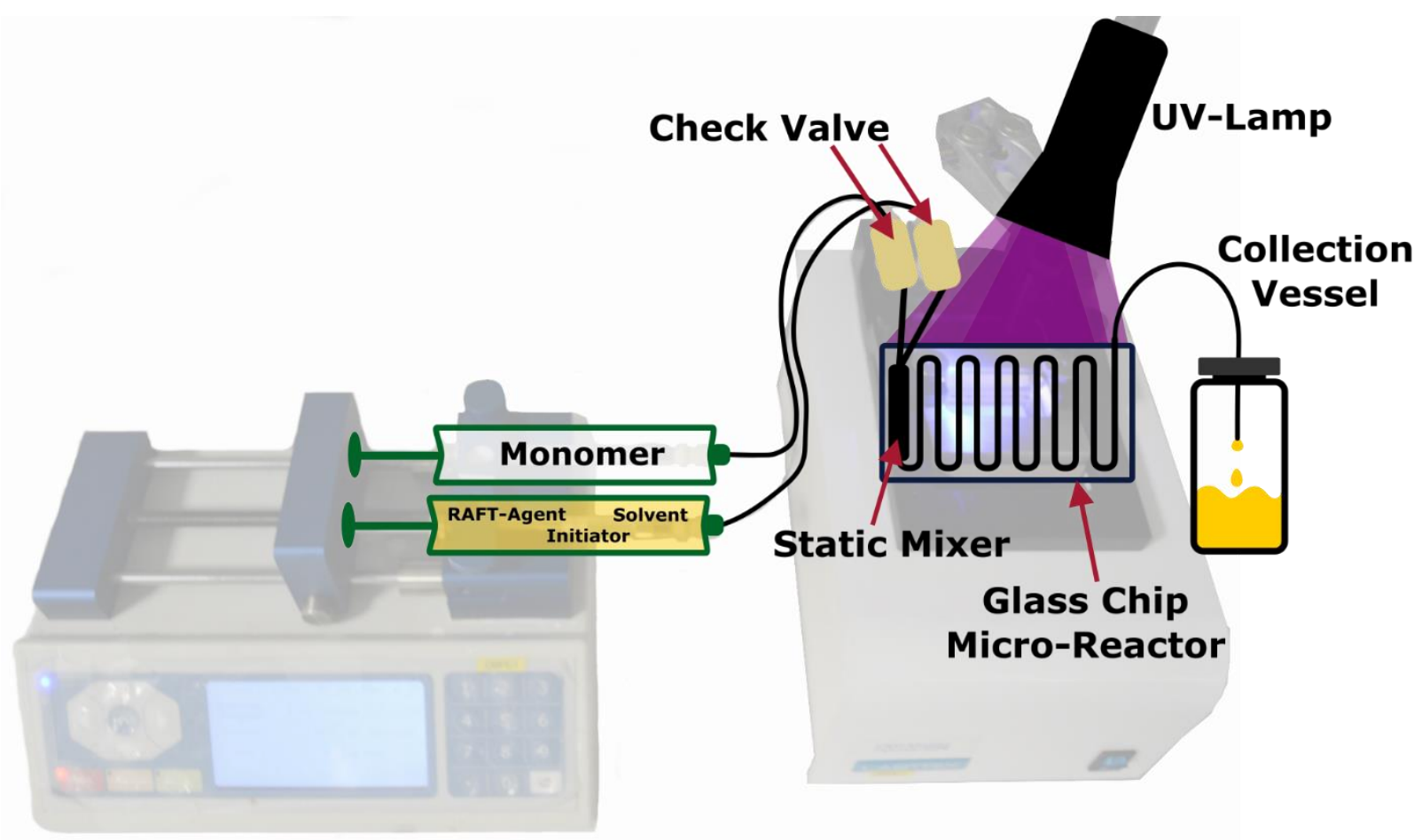

Figure 1 Illustration of the used microflow reactor (Chemtrix Labtrix Start). 


\section{Reaction Condition Optimization}

First, different ratios between the photo initiator benzoin and the RAFT-agent DoPAT were screened in order to identify optimal conditions with respect to reaction rate and achievable yield. As standard reaction conditions, a light intensity of $17 \mathrm{~mW} \mathrm{~cm}^{-2}$ and a temperature of 25 ${ }^{\circ} \mathrm{C}$ were set. Employment of flow reactors allows for isothermal reaction conditions, despite the exothermicity of acrylate polymerizations. ${ }^{19}$ For the first screening, the monomer to RAFT agent ratio was kept at 80:1 and the photo initiator ratio varied between $0.05,0.25,0.50$ and 1.00 with respect to the RAFT agent. In this particular test, benzoin was used as photo initiator. The analysis of the obtained samples show a larger dispersity with increasing benzoin concentration (Figure 2). The measured number average molecular weights increases linearly with time for the tested DoPAT to benzoin ratios up to 1:0.50. Molar masses of up to $8700 \mathrm{~g} \mathrm{~mol}^{-1}$ were reached. At the highest initiator concentration, a levelling off at around 7000 $\mathrm{g} \mathrm{mol}^{-1}$ is observed with dispersities being raised to 1.6. With increasing initiator concentration, faster reaction rates are generally noticed as should be expected. Monomer conversion went up from $23 \%$ for $1: 0.05$ via $62 \%(1: 0.25), 63 \%(1: 0.50)$ to $82 \%$ for the $1: 1.00$ DoPAT to benzoin ratio for 20 min maximum reaction time. The ratio of 1:0.25 shows relatively high conversions, and no significantly slower polymerizations compared to the higher initiator concentrations, while retaining reasonable dispersities in the range of 1.2. 
Mostly, the influence of temperature on photopolymerizations is neglected in fundamental studies. Yet, polymerizations are associated with considerable exothermicity, and also many light sources create significant heat so that reactions are often carried out significantly above room temperature. For any photopolymerization temperature has a distinct effect, since the chain growth reaction itself is essentially still thermally activated. Hence, an increase in temperature should directly lead to an increase in the polymerization rate, even if this effect was for example not directly confirmed for photo-induced copper-mediated polymerization (photoCMP) reactions. ${ }^{20}$ The employed reactor setup allows to tune temperature independent

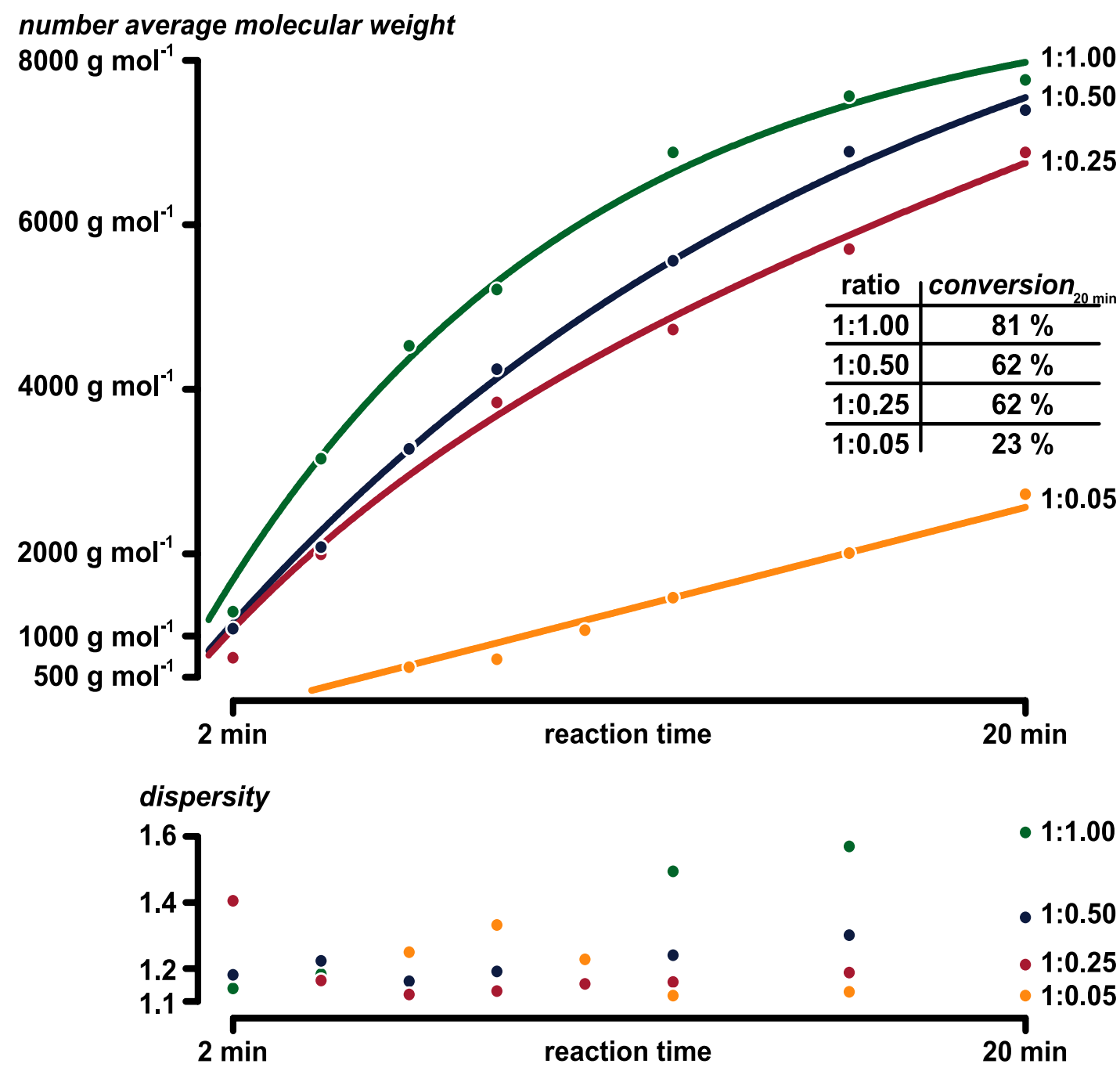

Figure 2 Influence of different initiator concentrations on the development of number average molecular weight and dispersities of a photoRAFT polymerization of $n \mathrm{BA}$ with increasing reaction time. The reactions were carried out at $25^{\circ} \mathrm{C}$ with a light intensity of $17 \mathrm{~mW} \mathrm{~cm}{ }^{-2}$ in butyl acetate as solvent. As monomer ( $n$ BA) to RAFT agent (DoPAT) ratio 80:1 was employed with varying the initiator (benzoin) ratios to $0.05,0.25,0.50$ and 1.00 with respect to the RAFT agent concentration. 


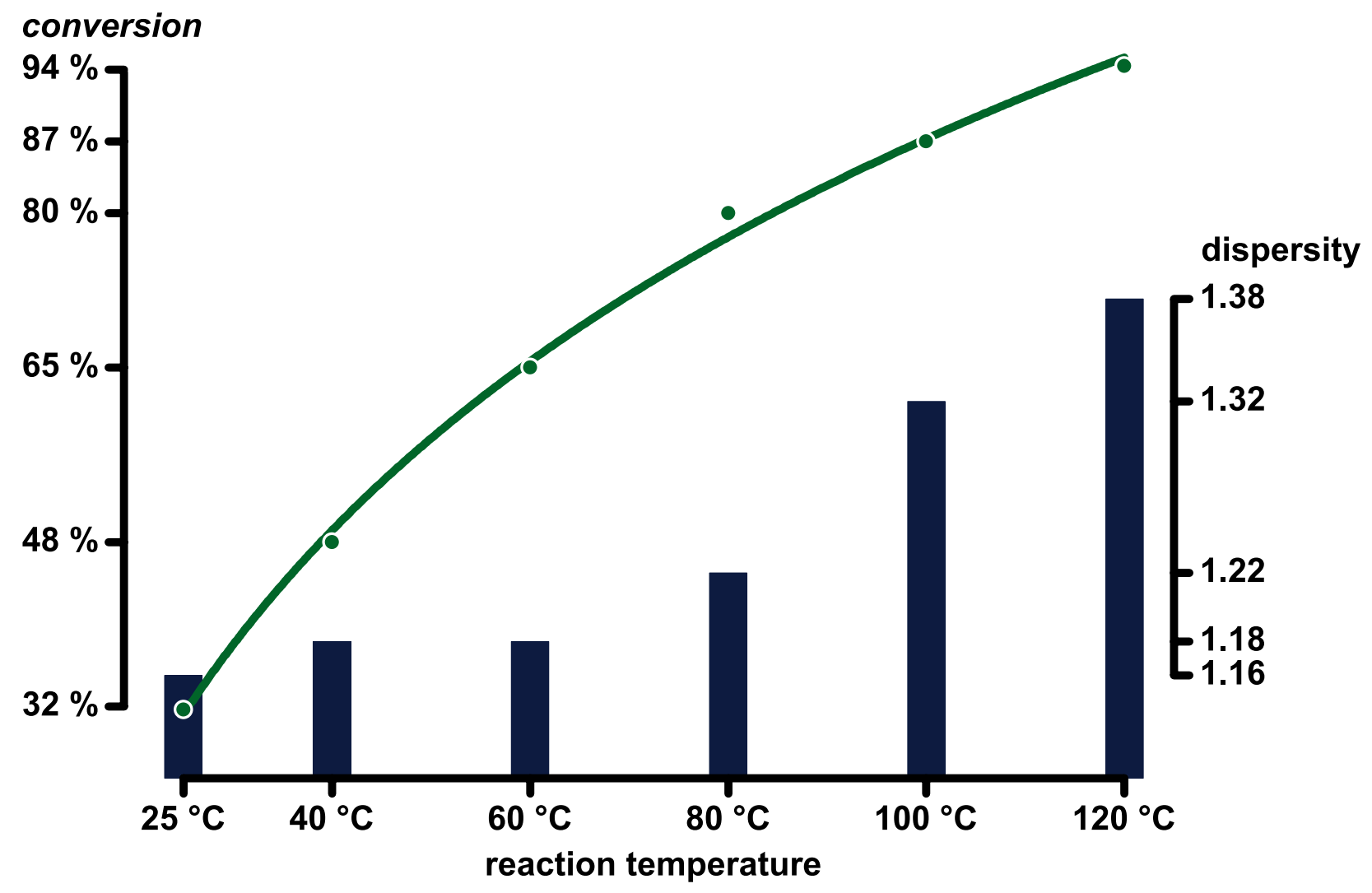

Figure 3 Increasing monomer conversion with higher reaction temperatures for a photoRAFT polymerization of $n$ BA. Monomer conversion was determined after a reaction time of 12 minutes with a light intensity of $17 \mathrm{~mW} \mathrm{~cm}^{-2}$. As DoPAT to benzoin to $n$ BA ratio 1:0.25:80 was used with butyl acetate as solvent.

of light source heat-up, and in order to test the exact effect on the photo-initiated RAFT polymerization, the temperature was increased gradually from 25 to $120{ }^{\circ} \mathrm{C}$ in the microflow device (note that higher temperatures lead to decomposition of RAFT end groups and hence a breakdown of reaction control). Figure 2 depicts the results of this series for DoPAT to benzoin to $n \mathrm{BA}$ ratios of 1:0.25:80 in BuAc with a light intensity of $17 \mathrm{~mW} \mathrm{~cm}^{-2}$. The reaction time was set to 12 minutes for all temperatures. In Figure 3, the increasing monomer conversion with higher reaction temperature is clearly confirmed, demonstrating that almost full conversion of the polymerization can be reached at the highest temperature, while room temperature only affords for roughly $32 \%$ conversion in the same time span. As negative side effect, an increase in the dispersity of the obtained polymer was noticed. The dispersities stay below 1.2 for reaction temperatures up to $60{ }^{\circ} \mathrm{C}$. For temperatures above $100{ }^{\circ} \mathrm{C}$, dispersities exceeding 1.3 were measured. The largely increased dispersity at $120{ }^{\circ} \mathrm{C}$ is an indication of the onset of trithiocarbonate elimination setting in. ${ }^{14,21}$ Additionally, also $\beta$-scission of acrylate-typical midchain radicals stemming from transfer to polymer reactions contribute to the broadening. 
These dispersity results are in agreement with literature known behaviour of trithiocarbonate controlled RAFT polymerizations, and hence not only typical for photopolymerizations. ${ }^{22}$ As mentioned above, we optimized polymerization with regards to the precision that can be reached, and hence $60{ }^{\circ} \mathrm{C}$ was chosen for the following polymerizations as standard temperature, so as to allow for moderately increased yields, but also maintaining a low overall dispersity.

For the next optimization step, the influence of the light intensity on the reaction rate was investigated, at $60{ }^{\circ} \mathrm{C}$ reaction temperature. Monomer conversions with increasing reaction times and light intensities are depicted in Figure 4. Unsurprisingly, an increase in light intensity is followed by an increase of the reaction rate. For an intensity of $5 \mathrm{~mW} \mathrm{~cm}^{-2}$ only $68 \%$ monomer conversion was reached after 20 minutes reaction time. With increasing intensities higher conversion can be achieved, reaching $86 \%$ at an intensity of $30 \mathrm{~mW} \mathrm{~cm}^{-2}$ under otherwise identical conditions. However, for higher intensities only rather insignificant

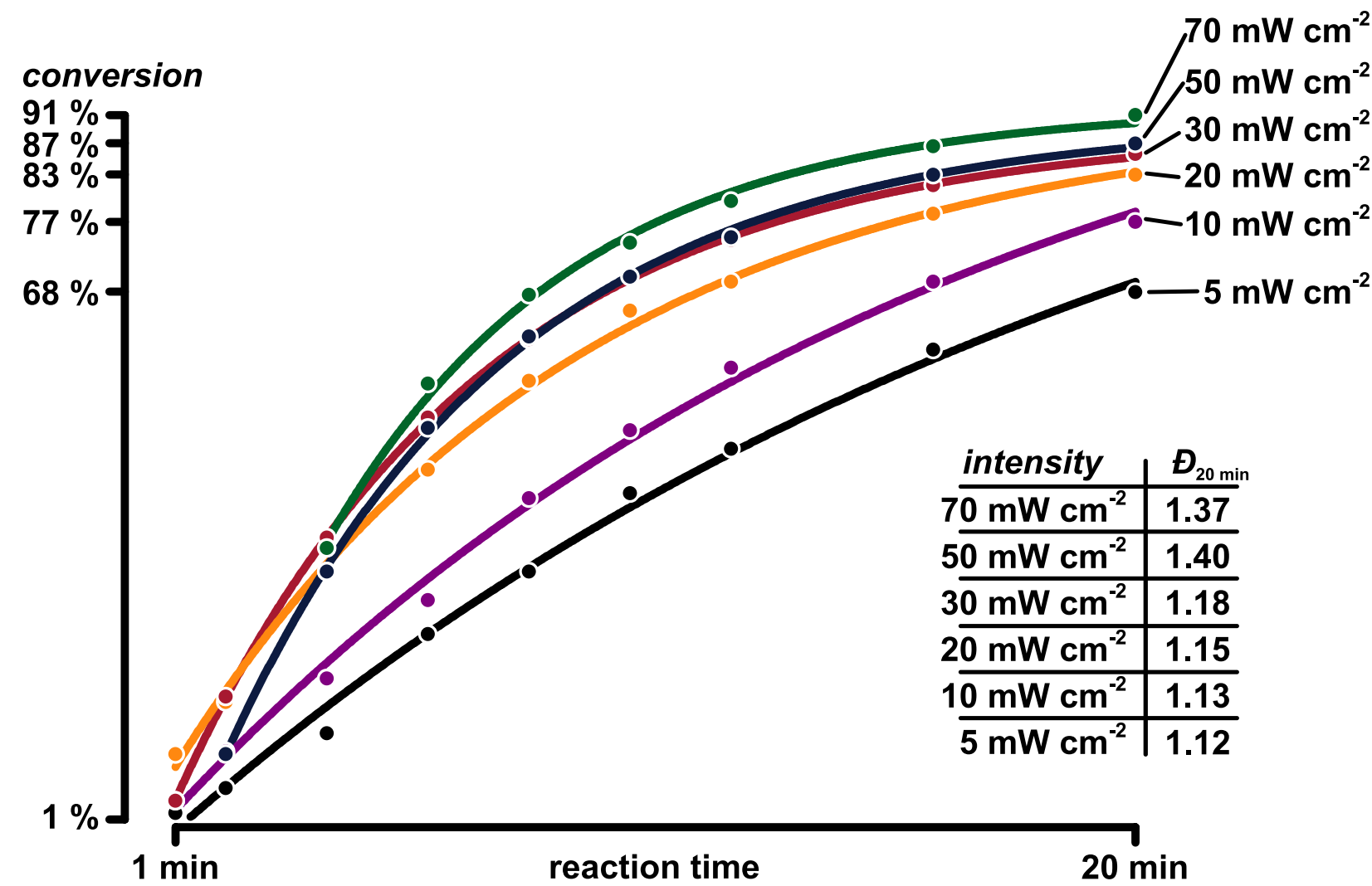

Figure 4 Influence of light intensity on the reaction rate of a photo-initiated RAFT polymerization of $n \mathrm{BA}$ in a microflow reactor. As light source an Omnicure S1000 system with a peak wavelength at $365 \mathrm{~nm}$ was used. Ratios of 1:0.25:80 for DoPAT, benzoin and $n \mathrm{BA}$ were used with $\mathrm{BuAc}$ as solvent. All reactions were performed at $60^{\circ} \mathrm{C}$. 
increases in monomer conversion were observed $\left(70 \mathrm{~mW} \mathrm{~cm}^{-2}, 91 \%\right)$, indicating that 30 $\mathrm{mW} \mathrm{cm} \mathrm{cm}^{-2}$ marks a point of complete light saturation in the reactor, after which no further significant increase can be observed. Also, from the same light intensity on, deviations from linear first order plots are observed, indicating that an increase of light intensity goes alongside with a change in initiation mechanism over time (see below for a discussion of initiator decay rates). Regardless, combining all above optimization steps, the best reaction conditions for the photoRAFT polymerizations are identified for a reaction temperature of $60^{\circ} \mathrm{C}$, a light intensity of $30 \mathrm{~mW} \mathrm{~cm}^{-2}$ and a benzoin molar ratio of $0.25: 1$ with respect to the DoPAT concentration. For all optimization reactions a monomer to RAFT agent ratio of 80:1 was used. Reactions were carried out in a $50 \%$ butyl acetate solution.

\section{Chain length variation}

To demonstrate the robustness of the photoinduced RAFT polymerization, the RAFT-agent to monomer ratio was varied. Target degrees of polymerization of 160 lead to polymers with number average molecular weight of $20000 \mathrm{~g} \mathrm{~mol}^{-1}$. Figure 5 shows the resulting molecular weight distributions for polymerization in presence of benzoin and in absence of any photoinitiator. In both cases, an increase in molecular weight with decreasing RAFT agent
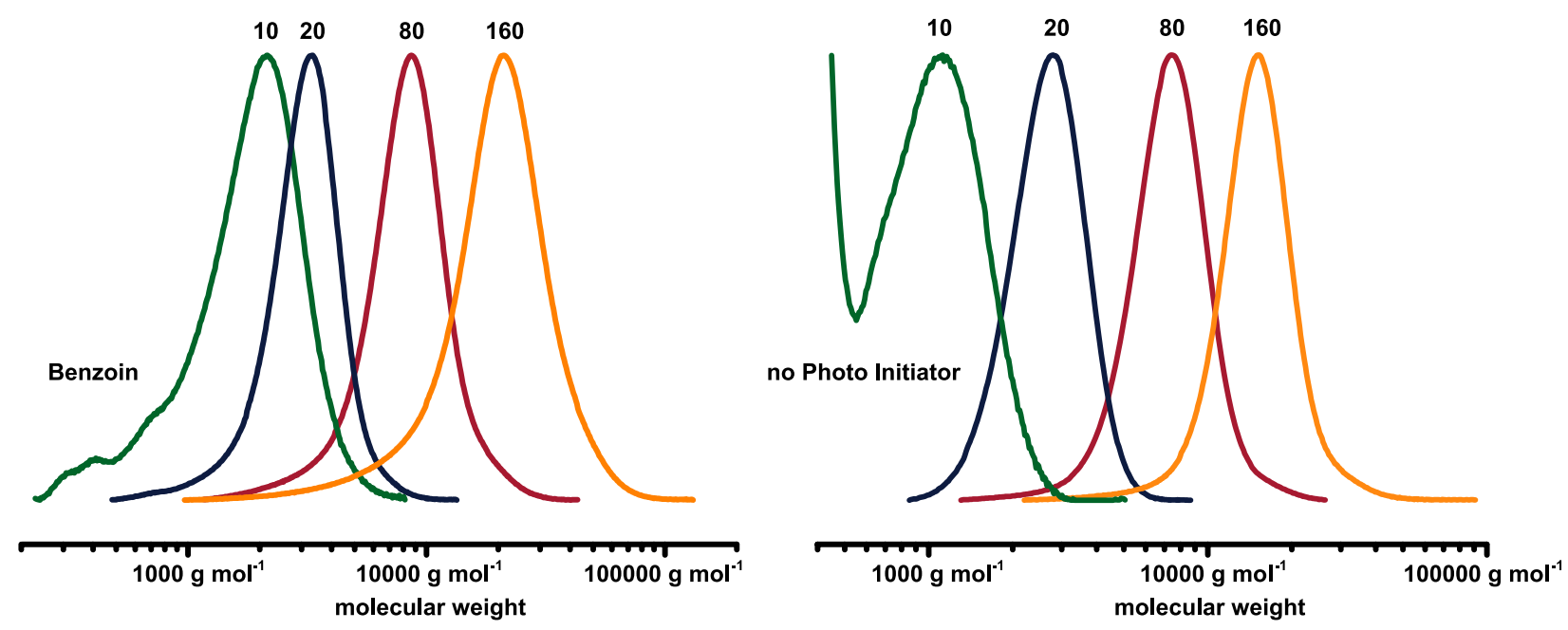

Figure 5 The degree of polymerization was varied in $n \mathrm{BA}$ polymerizations with benzoin (left) as initiator and without initiator (right). Molar ratios of 10, 20, 80 and 160 with respect to the RAFT-agent were polymerized. Reactions were performed at $60{ }^{\circ} \mathrm{C}$ in butyl acetate in a microflow reactor with a light intensity of $30 \mathrm{~mW} \mathrm{~cm}^{-2}$. 
concentrations is seen as should be expected for an ideal RAFT polymerization. Reactions in presence of benzoin are faster, but dispersities are slightly increased (reaching 1.36 in the highest case). In contrast, the polymer from the photoiniferter route did not show any fronting and the dispersities stayed in the range of 1.10 over the whole chain length regime due to the much lower radical flux and the fact that reversible iniferter termination leads to formation of macroRAFT agent, and hence does not contribute to broadening of the distribution, in contrast to irreversible termination of initiator-derived radicals..

\section{Block Copolymer Synthesis}

As mentioned above, photoRAFT polymerizations should be able to yield block copolymers if the endgroup fidelity is not compromised in the reaction. From the above optimizations, it is obvious that the photoinitiators have a slightly negative influence on dispersity, which is typically associated with a loss of endgroup fidelity. It should be noted that not only the trithiocarbonate RAFT endgroup is thereby of interest, but also the $\alpha$-chain end, where the RAFT R-group may be replaced by an initiator fragment. ${ }^{23}$ For block copolymers, the first block represents the R-group in chain extension and $\mathrm{R}$ group replacement leads to a loss of the block structure even if the process is fully living with respect to the trithiocarbonate endgroup. The structural fidelity of the RAFT polymers was investigated via electrospray ionization mass spectrometry (ESI-MS). A $\mathrm{p}(n \mathrm{BA})$ sample made in the microflow reactor with the above described optimized reaction conditions was measured and a high end group fidelity is observed (see Figure S4 and S5 and Table S2), indicating that block copolymers with high purity may be achievable, even if some small peaks indicating side product formation are present.

Chain extension was hence approached, and a $n$ BA polymer $\left(M_{\mathrm{n}}=3000 \mathrm{~g} \mathrm{~mol}^{-1}, Ð=1.18\right)$ was used as macrotransfer agent for methyl acrylate polymerization with molar ratios of 1:0.25:20 


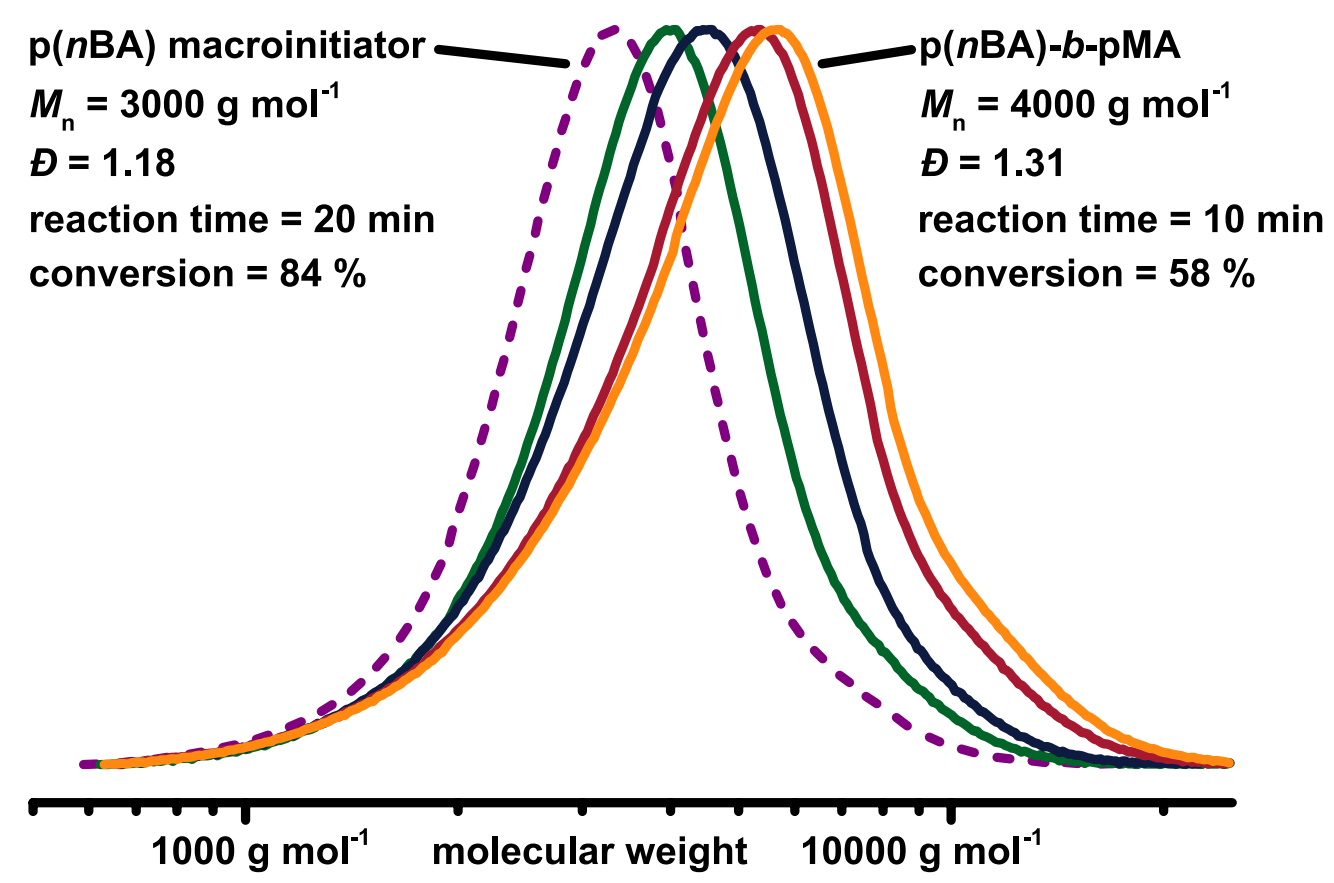

Figure 6 Molecular weight distributions for the synthesized $\mathrm{p}(n \mathrm{BA})-b$-pMA block copolymer via photo induced RAFT polymerization in a microflow reactor. A shift to higher masses is observed, showing the possibility to reactivate the $\mathrm{p}(n \mathrm{BA})$ macroinitiator.

for $\mathrm{p}(n \mathrm{BA})$ to benzoin to $\mathrm{MA}$ at $60^{\circ} \mathrm{C}$ and with $30 \mathrm{~mW} \mathrm{~cm}{ }^{-2}$ in the microflow reactor setup. A diblock p $(n \mathrm{BA})-b$-pMA copolymer with a molar mass of $4000 \mathrm{~g} \mathrm{~mol}^{-1}$ was obtained (see Figure 6), with increasing molecular weight over the whole polymerization time. The reaction reached a monomer conversion of $58 \%$ after 10 minutes, hence the rate of polymerization in the chain extension was in line with the homopolymerizations. Theoretical $\left(3990 \mathrm{~g} \mathrm{~mol}^{-1}\right)$ and measured $\left(4000 \mathrm{~g} \mathrm{~mol}^{-1}\right)$ molecular weights are in almost perfect agreement. However, after the chain extension, a slightly higher dispersity of 1.31 is observed. Compared to thermal RAFT polymerizations, such dispersity is not an uncommon result for block copolymerizations, even if more narrow distributions are achievable by optimization. Yet, such dispersity is encouraging and most likely also more block extensions could be achieved and the in-here used method seems to be in line with most other conventional RDRP methods. ${ }^{24}$ 


\section{Variation of photo initiators}

After optimal polymerization conditions for fast synthesis of low dispersity RAFT polymers had been identified, further tests were carried out on the choice of initiator itself. A variation of commercially available and commonly used photoinitiators were systematically tested and compared. Beside the before mentioned benzoin, 2,2-dimethoxy-2-phenylacetophenone (DMPA), phenylbis(2,4,6-trimethylbenzoyl)phosphine oxide (Irgacure 819) and 2-hydroxy-4'(2-hydroxyethoxy)-2-methylpropiophenone (Irgacure 2959) were used (see Scheme 2 for structures). Additionally, the pure photoiniferter reaction was compared to complete the overview and to elucidate which role the initiator plays in the photoRAFT reaction.<smiles>O=C(c1ccccc1)C(O)c1ccccc1</smiles>

Benzoin<smiles>Cc1cc(C)c(C(=O)P(=O)(C(=O)c2c(C)cc(C)cc2C)c2ccccc2)c(C)c1</smiles>

IRGACURE 819<smiles>COC(OC)(C(=O)c1ccccc1)c1ccccc1</smiles>

DMPA<smiles>CC(C)(O)C(=O)c1ccc(OCCO)cc1</smiles>

IRGACURE 2959

Scheme 2 Chemical structures of the used photoinitiators. 
Table 1 Molecular weights and dispersity for polymers made with various photoinitiators and in absence of conventional initiator. All reactions were carried out in butyl acetate with $n$-butyl acrylate as monomer. Reactions were performed in a microflow reactor at $60{ }^{\circ} \mathrm{C}$ with a reaction time of 20 minutes and a light intensity of $30 \mathrm{~mW} \mathrm{~cm}$.

\begin{tabular}{|c|c|c|c|c|c|c|}
\hline & Initiator & $\begin{array}{c}\text { Molar Ratio } \\
\text { M:R:I }\end{array}$ & Conversion & $\begin{array}{l}M_{\mathrm{n}, \text { theory }} \\
{\left[\mathrm{g} \mathrm{mol}^{-1}\right]}\end{array}$ & $\begin{array}{c}M_{\mathbf{n}, \mathbf{G P C}} \\
{\left[\mathrm{g} \mathrm{mol}^{-1}\right]}\end{array}$ & $\boldsymbol{\oplus}$ \\
\hline $\mathbf{1}^{\mathrm{a}}$ & - & $80: 1: 0$ & $61 \%$ & 7200 & 6800 & 1.12 \\
\hline 2 & Benzoin & $20: 1: 0.25$ & $85 \%$ & 2700 & 3100 & 1.18 \\
\hline 3 & DMPA & $20: 1: 0.25$ & $87 \%$ & 2800 & 3000 & 1.18 \\
\hline 4 & Irgacure 819 & $20: 1: 0.25$ & $88 \%$ & 2800 & 3600 & 1.55 \\
\hline 5 & Irgacure 2959 & $20: 1: 0.25$ & $94 \%$ & 3000 & 3500 & 1.20 \\
\hline
\end{tabular}

The initiators were tested for $n \mathrm{BA}$ in BuAc under the previously optimized reaction conditions $\left(30 \mathrm{~mW} \mathrm{~cm}^{-2}, 60{ }^{\circ} \mathrm{C}\right)$. Again, all initiators were used with a molar ratio of 0.25 to

\section{$\ln \left([M]_{0} /[M]_{t}\right)$}

\section{0}

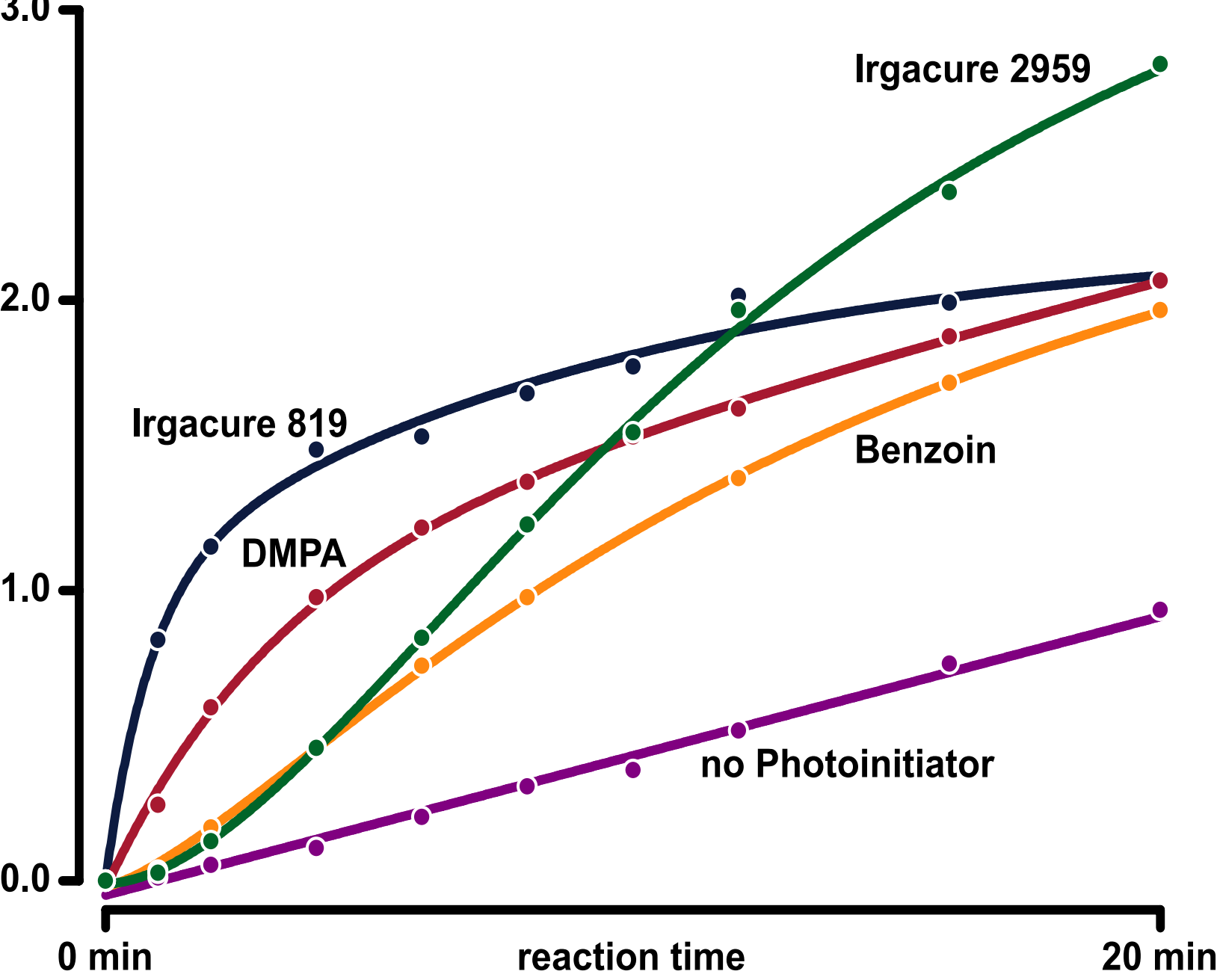

Figure 7 Kinetic first-order plots for photoRAFT polymerization of $n$-butyl acrylate in butyl acetate using different initiators. All reactions were performed in a microflow reactor at $60{ }^{\circ} \mathrm{C}$ with a light intensity of $30 \mathrm{~mW} \mathrm{~cm}{ }^{-2}$. 
the RAFT agent. The obtained conversions, number average molecular weights and dispersities are collated in

Table 1. A strong variation in polymerization rate for the various photoinitiator is observed and the rate of polymerization for photoRAFT polymerization in absence of photoinitiators is on first glance relatively high. Conversions increased from $61 \%$ for the photoiniferter reaction up to $94 \%$ for Irgacure 2959 at 20 minutes reaction time. Dispersities stayed in a range of 1.1 to 1.2 for all reactions apart from the Irgacure 819 initiated one. For this specific initiator, a dispersity of 1.55 is measured, which may be explained by the complex dissociation of the Irgacure 819 initiator, which is associated with two photolabile bonds within the molecule. ${ }^{5 b}$ Consequently, a polymer chain carrying a 819 fragment can itself act as a macrophotoinitiator, effectively broadening the distribution. ${ }^{25}$ Interestingly, for the DMPA and Irgacure 819 initiated reactions, a fast increase in monomer conversion is observed in the first minutes of the reaction after which the first order plot becomes almost linear, indicating a switch in the initiation mechanism (note that the photoiniferter reaction seems to follow almost linear behavior). Such change in slope may indicate a change in mechanism upon complete consumption of the initiator. In order to understand the differences between the initiators, the decomposition rates of benzoin and Irgacure 2959 were determined at $360 \mathrm{~nm}$. For benzoin, a pseudo zeroth order decomposition rate of $8.1 \cdot 10^{-5} \mathrm{M} \mathrm{s}^{-1}$ and for Irgacure 2959 of $13.0 \cdot 10^{-5} \mathrm{M} \mathrm{s}^{-1}$ was calculated 
(determination of rate coefficients for photoinduced reactions is complex and only valid for distinct light sources and intensity profiles, for details the reader is referred to the Supporting Information) for the given light intensity. This corresponds to full decomposition of both initiators within 5-10 minutes under the given conditions, whereby the faster polymerization that is observed for Irgacure 2959 is in good agreement with the higher decomposition rate coefficient. Overall, as the initial concentration of initiator and hence the number of radicals generated is in all cases studied identical, the variation in reaction rate can only be explained by the variation of decomposition rates (It should be additionally noted that of course also the reactivity of the generated radical fragments plays a significant role; the exact effects are, however complex and the decomposition rate is the first decisive factor). Yet, the relation between fast decomposition and rate of polymerization is not straight forward, as overproduction of radicals also leads to increased termination and hence broadening of distributions and eventually slowing down of the reaction. In any case, it is an important observation that photoRAFT polymerizations in flow seem to carry on after consumption of all initiator, thus making these polymerizations hybrids between classically-initiated RAFT and photoiniferter RAFT polymerizations. In fact, also in the beginning of the reactions, a significant contribution of the photoiniferter mechanism to the total initiation must be expected. The initiator may hence merely act as a booster for the reaction at short reaction times. Yet, the choice of initiator has a significant effect on the monomer conversion that can be reached within a certain time span, and while benzoin seems to be a good average choice as initiator, Irgacure 2959 shows the best results for rate of reaction as well as dispersity of the residual polymer (note that a slightly higher dispersity is justified if a higher conversion is reached).

\section{Conclusion}


PhotoRAFT polymerizations of butyl acrylate have been studied in depth for polymerizations initiated by conventional radical photoinitiators. Polymerizations can be optimized to reach high monomer conversions within minutes of time, and yield materials that are comparable with regards to chain length control, dispersity and chain end fidelity to conventional RAFT polymerization. Interestingly, a clear temperature dependence of the polymerization rate is observed, and photoRAFT at $60^{\circ} \mathrm{C}$ at intermediate light intensity marks the optimum reaction condition to perform polymerizations. PhotoRAFT in presence of commercially available initiators are simple to be carried out, removing the need for using elaborate photocatalysts if light if the application of UV light is not disadvantageous. Polymerizations can also be compared to photoRAFT reactions that proceed via a photoiniferter initiation mechanism as recently brought forward. The choice of initiator plays a very significant role with respect to the outcome of the polymerization, especially with regards to the overall polymerization rate. The differences seen for the various initiators can be routed to the decomposition rate of the initiators, whereby some initiators decay faster than the runtime of a typical polymerization, indicating that the photoiniferter initiation becomes the dominant driver for the polymerizations, even if exogenous photoinitiators had been initially added. The interplay between photoiniferter reactions and the contribution of the photoinitiators to the overall polymerization rate is currently under further investigation in our laboratories.

\section{ASSOCIATED CONTENT}

Supporting Information. Further information on materials and methods, the determination of initiator decay rate coefficients and the elucidation of endgroup fidelity by ESI-MS is found in the support information. This material is available free of charge via the Internet at http://pubs.acs.org. 


\section{AUTHOR INFORMATION}

\section{Corresponding Author}

* Thomas Junkers, Email: thomas.junkers@uhasselt.be, Homepage: www.polymatter.net,

Twitter: @prd_group

\section{Author Contributions}

The manuscript was written through contributions of all authors. All authors have given approval to the final version of the manuscript.

\section{ACKNOWLEDGMENT}

The authors are grateful for support by the Belgian Science Policy (Belspo) via the Interuniversity Attraction Poles Program IAP P7/05 "Functional Supramolecular Systems". T.J. wishes to thank the Fonds Wetenschappelijk Onderzoek (FWO) for a research grant. Furthermore, assistance in laboratory work during an internship of Gianfranco Padulla Nardini is kindly acknowledged.

\section{REFERENCES}

1. Pan, X.; Tasdelen, M. A.; Laun, J.; Junkers, T.; Yagci, Y.; Matyjaszewski, K., Photomediated Controlled Radical Polymerization. Prog. Polym. Sci. 2016.

2. Oelgemoeller, M., Highlights of Photochemical Reactions in Microflow Reactors. Chem. Eng. Technol. 2012, 35 (7), 1144-1152.

3. Oelgemöller, M.; Shvydkiv, O., Recent Advances in Microflow Photochemistry. Molecules 2011, 16 (9), 7522-7550.

4. Junkers, T.; Wenn, B., Continuous photoflow synthesis of precision polymers. React. Chem. Eng. 2016, 1 (1), 60-64.

5. (a) Hook, B. D. A.; Dohle, W.; Hirst, P. R.; Pickworth, M.; Berry, M. B.; Booker-Milburn, K. I., A Practical Flow Reactor for Continuous Organic Photochemistry. J. Org. Chem. 2005, 70 (19), 7558-7564; (b) Gardiner, J.; Hornung, C. H.; Tsanaktsidis, J.; Guthrie, D., Continuous flow photo-initiated RAFT polymerisation using a tubular photochemical reactor. Eur. Polym. J. 2016, 80, 200207.

6. Chen, M.; Zhong, M.; Johnson, J. A., Light-Controlled Radical Polymerization: Mechanisms, Methods, and Applications. Chem. Rev. 2016. 
7. (a) Chuang, Y.-M.; Wenn, B.; Gielen, S.; Ethirajan, A.; Junkers, T., Ligand switch in photoinduced copper-mediated polymerization: synthesis of methacrylateacrylate block copolymers. Polym. Chem. 2015, 6 (36), 6488-6497; (b) Wenn, B.; Conradi, M.; Carreiras, A. D.; Haddleton, D. M.; Junkers, T., Photo-induced coppermediated polymerization of methyl acrylate in continuous flow reactors. Polym. Chem. 2014, 5 (8), 3053-3060.

8. Melker, A.; Fors, B. P.; Hawker, C. J.; Poelma, J. E., Continuous flow synthesis of poly(methyl methacrylate) via a light-mediated controlled radical polymerization. $J$. Polym. Sci., Part A: Polym. Chem. 2015, 53 (23), 2693-2698.

9. Kermagoret, A.; Wenn, B.; Debuigne, A.; Jerome, C.; Junkers, T.; Detrembleur, C., Improved photo-induced cobalt-mediated radical polymerization in continuous flow photoreactors. Polym. Chem. 2015, 6 (20), 3847-3857.

10. Chen, M.; Johnson, J. A., Improving photo-controlled living radical polymerization from trithiocarbonates through the use of continuous-flow techniques. Chem. Commun. 2015, 51 (31), 6742-6745.

11. (a) Xu, J.; Shanmugam, S.; Duong, H. T.; Boyer, C., Organo-photocatalysts for photoinduced electron transfer-reversible addition-fragmentation chain transfer (PETRAFT) polymerization. Polym. Chem. 2015, 6 (31), 5615-5624; (b) Jung, K.; Xu, J.; Zetterlund, P. B.; Boyer, C., Visible-Light-Regulated Controlled/Living Radical Polymerization in Miniemulsion. ACS Macro Letters 2015, 4 (10), 1139-1143; (c) Shanmugam, S.; Xu, J. T.; Boyer, C., Photoinduced Electron Transfer-Reversible Addition-Fragmentation Chain Transfer (PET-RAFT) Polymerization of Vinyl Acetate and N-Vinylpyrrolidinone: Kinetic and Oxygen Tolerance Study. Macromolecules 2014, 47 (15), 4930-4942.

12. McKenzie, T. G.; Fu, Q.; Wong, E. H. H.; Dunstan, D. E.; Qiao, G. G., Visible Light Mediated Controlled Radical Polymerization in the Absence of Exogenous Radical Sources or Catalysts. Macromolecules 2015, 48 (12), 3864-3872.

13. (a) Lalevee, J.; Blanchard, N.; El-Roz, M.; Allonas, X.; Fouassier, J. P., New Photoiniferters: Respective Role of the Initiating and Persistent Radicals. Macromolecules 2008, 41 (7), 2347-2352; (b) Lalevée, J.; Allonas, X.; Fouassier, J. P., A New Efficient Photoiniferter forLivingRadical Photopolymerization.

Macromolecules 2006, 39 (24), 8216-8218; (c) Qin, S. H.; Qiu, K. Y., A new polymerizable photoiniferter for preparing poly(methyl methacrylate) macromonomer. Eur. Polym. J. 2001, 37 (4), 711-717; (d) de Boer, B.; Simon, H. K.; Werts, M. P. L.; van der Vegte, E. W.; Hadziioannou, G., "Living" Free Radical Photopolymerization Initiated from Surface-Grafted Iniferter Monolayers. Macromolecules 2000, 33 (2), 349-356; (e) Otsu, T.; Yoshida, M., Role of initiator-transfer agent-terminator (iniferter) in radical polymerizations: Polymer design by organic disulfides as iniferters. Makromol. Chem., Rapid Commun. 1982, 3 (2), 127-132.

14. Moad, G.; Rizzardo, E.; Thang, S. H., Radical addition-fragmentation chemistry in polymer synthesis. Polymer 2008, 49 (5), 1079-1131.

15. Gody, G.; Zetterlund, P. B.; Perrier, S.; Harrisson, S., The limits of precision monomer placement in chain growth polymerization. Nat Commun 2016, 7, 10514. 16. Ferguson, C. J.; Hughes, R. J.; Nguyen, D.; Pham, B. T.; Gilbert, R. G.; Serelis, A. K.; Such, C. H.; Hawkett, B. S., Ab Initio Emulsion Polymerization by RAFTControlled Self-Assembly. Macromolecules 2005, 38 (6), 2191-2204.

17. Strazielle, C.; Benoit, H.; Vogl, O., Preparation et caracterisation des polymeres tete-a-tete-VI. Proprietes physicochimiques du polystyrene tete-a-tete en solution diluee. Comparaison avec des polystyrenes de structure differente. Eur. Polym. J. 1978, 14 (5), 331-334. 
18. (a) Ham, M.-K.; HoYouk, J.; Kwon, Y.-K.; Kwark, Y.-J., Photoinitiated RAFT polymerization of vinyl acetate. J. Polym. Sci., Part A: Polym. Chem. 2012, 50 (12), 2389-2397; (b) Yang, X. M.; Qiu, K. Y., Radical Polymerization of Styrene Initiated with Alkyl N,N-Diethyldithiocarbamylacetate Photoiniferters. Journal of Macromolecular Science, Part A 1997, 34 (2), 315-325. (c) Lu, L.; Zhang, H.; Yang, N.; Cai, Y, Macromolecules 2006, 39, 3770-3776.

19. Derboven, P.; Van Steenberge, P. H. M.; Vandenbergh, J.; Reyniers, M.-F.; Junkers, T.; D'Hooge, D. R.; Marin, G. B., Improved Livingness and Control over Branching in RAFT Polymerization of Acrylates: Could Microflow Synthesis Make the Difference? Macromol. Rapid Commun. 2015, 36 (24), 2149-55.

20. Railian, S.; Wenn, B.; Junkers, T., Photo-induced copper-mediated acrylate polymerization in continuous-flow reactors. J. Flow Chem. 2016, 06, 1-8.

21. (a) Moad, G.; Rizzardo, E.; Thang, S. H., Living Radical Polymerization by the RAFT Process. Austral. J. Chem. 2005, 58 (6), 379; (b) Willcock, H.; O'Reilly, R. K., End group removal and modification of RAFT polymers. Polym. Chem. 2010, 1 (2), 149-157; (c) Postma, A.; Davis, T. P.; Moad, G.; O'Shea, M. S., Thermolysis of RAFT-Synthesized Polymers. A Convenient Method for Trithiocarbonate Group Elimination. Macromolecules 2005, 38 (13), 5371-5374.

22. Hornung, C. H.; Postma, A.; Saubern, S.; Chiefari, J., Sequential flow process for the controlled polymerisation and thermolysis of RAFT-synthesised polymers. Polymer 2014, 55 (6), 1427-1435.

23. Vandenbergh, J.; Junkers, T., Alpha and Omega: Importance of the Nonliving Chain End in RAFT Multiblock Copolymerization. Macromolecules 2014, 47 (15), 5051-5059.

24. (a) Chuang, Y.-M.; Ethirajan, A.; Junkers, T., Photoinduced SequenceControlled Copper-Mediated Polymerization: Synthesis of Decablock Copolymers. ACS Macro Letters 2014, 3 (8), 732-737; (b) Anastasaki, A.; Nikolaou, V.; McCaul, N. W.; Simula, A.; Godfrey, J.; Waldron, C.; Wilson, P.; Kempe, K.; Haddleton, D. M., Photoinduced Synthesis of $\alpha, \omega$-Telechelic Sequence-Controlled Multiblock Copolymers. Macromolecules 2015, 48 (5), 1404-1411.

25. Szablan, Z.; Junkers, T.; Koo, S. P. S.; Lovestead, T. M.; Davis, T. P.; Stenzel, M. H.; Barner-Kowollik, C., Mapping Photolysis Product Radical Reactivities via Soft Ionization Mass Spectrometry in Acrylate, Methacrylate, and Itaconate Systems.

Macromolecules 2007, 40 (19), 6820-6833. 
Table of Contents Graphic

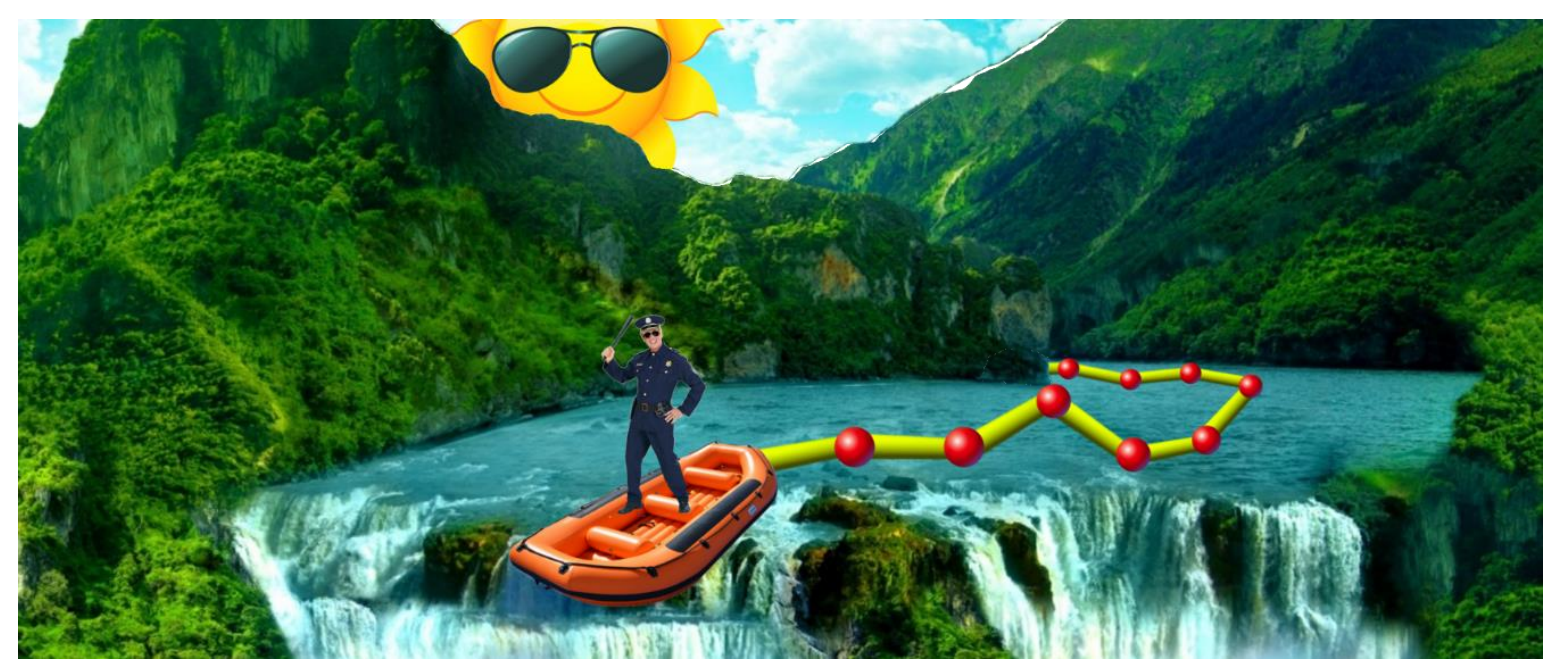

